\section{Nicht alle Wege führen nach Rom}

\author{
E. Taverna
}

Das flach hügelige Land wirkt ausgedörrt. Die grossscholligen Äcker sind dunkelbraun und das verfilzte Gras am Wegrand fühlt sich an wie Stroh. Es ist still, nur der Wind schiebt die Wolkenschatten nach Süden. Irgendwo unter dem gepflügten Boden liegt die alte Via Cassia, läuft schnurgerade durchs Land, ein unsichtbares Band, das ab und zu auftaucht, wie ein grauer Wal. Unter den Füssen rascheln die Eichenblätter vom Vorjahr. Brombeerranken und Weissdorn verhaken sich in den Kleidern. Der schmale Pfad führt immer tiefer in den herbstlichen Wald, wo sich die Wildschweine vor den Jägern versteckt halten. Dann wird plötzlich ein bemooster Block sichtbar und dann noch einer, der fugenlos einen Randstein markiert. Wir gehen über graue Platten, die unversehrt aneinandergefügt unter dem Laub liegen. Erst da, wo der Hang zu einem tieferen Graben abfällt, endet die Strasse spurlos unter Zyklamen und rotbeerigem Mäusedorn.

Es gibt schönere Beispiele, die Via Appia, die bequem mit dem Auto zu besichtigen ist. Wer auf meterdickem Fundament mehr als 80000 Kilometer Pflaster verlegt, geht nicht so schnell vergessen. Doch selber entdecken macht mehr Spass und das Wandern wird zu einer Zeitreise. Unser Begleiter hat die Basaltblöcke in Fronarbeit freigelegt. In den Boden einer Kreuzung kratzt er die Geometrie der römischen Stadt, den Decumanus von Ost nach West, den Cardo von Nord nach Süd, das Forum im Kreuzpunkt, die Mitte der Welt. Wir haben dieses Muster im Kopf, können gar nicht anders, hängen fest in den Koordinaten dieses oder anderer Reiche, wie die Fliege im Netz. Mit der Cassia schneidet sich die Trajana, Parallelen, Hohlwege und Landwirtschaftsstrassen,

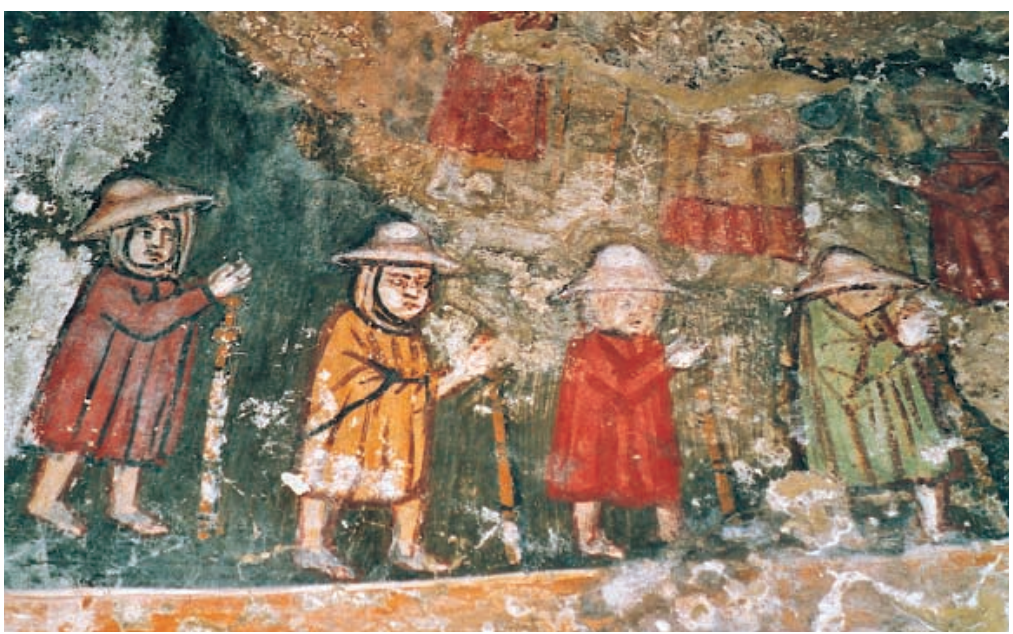

die vorbei an bellenden Hunden und schnatternden Enten auf dem Forum von Volsini über dem See von Bolsena enden. Die globale Römerwirtschaft hat ihre Spuren hinterlassen und zum lokalen Vulkangestein den rötlichen Granit und weissen Marmor herbeigeschafft. Alle Nachfahren haben sich daran bedient und die Säulen für Kirchen, Brunnen und Absperrungen gebraucht. Vom Interesse der Zementindustrie profitiert die archäologische Forschung, die den Mörtel der erhaltenen Mauern untersucht.

Wir wandern von Bolsena nach Montefiascone, Viterbo, den Vicosee, Sutri und dann über ein Stück der Via Flaminia auf den Monte Sorrate.

Im Netz der neuen und alten Strassen immer wieder die antiken Wegstücke, als Teil des beschilderten fränkischen Pilgerweges, von Traktoren befahren, als Einfahrt zu einem Gehöft, abseits in verwilderten Hecken und unzugänglichen Waldstücken. Oft sind die Bruchstücke erstaunlich lang und von imposanter Breite. Unverrückt liegt Block an Block, der Querschnitt leicht gewölbt, damit der Regen schneller abfliesst, als könnte ihnen die Zeit nichts anhaben.

Und weil sie stumm bleiben, erzählt Chris an ihrer Stelle von den Zügen der Goten und Langobarden, von Ortsheiligen und Märtyrern, den Begegnungen von Papst und Kaiser, von den Wallfahrten der Pilger und den Kutschenfahrten später Bildungsreisender wie Goethe senior oder Charles Dickens, die alle über das gleiche Pflaster gingen. Auch Mediziner schrieben Geschichte, wie jene von Johannes dem XXI, dem einzigen Arzt, der es zum Papst brachte. Er sass lieber über seinen Folianten im Palast von Viterbo, als mühsamen Regierungsgeschäften nachzureisen. Bis eines Tages die Bibliothek über ihm zusammenbrach und er von seinen Büchern erschlagen wurde. Fresken und Reliquien illustrieren die Legenden. Fussabdrücke in einer Steinplatte, Blut aus einer Hostie, das ein Tuch verfärbt hat. In der zweistöckigen Kirche San Flaviano läuft beim Portal ein Horrorfilm für die Analphabeten des päpstlichen Montefiascone. Eine Wand mit zerstückelten Kinderleichen aus Bethlehem, gefolgt von Marterszenen. Der höfisch gekleideten Dame wird die rechte Brust abgeschnitten und die halbentblösste Märtyrerin zwischen messerbestückten Rädern tranchiert. Nur der heilige Nikolaus rettet mit seiner Gabe drei Töchter vor dem Strich.

Noch einmal ein Abstecher im Tal der Treja in ein verwachsenes Gehölz voller Stacheln und würgender Waldreben. Der Pfad wird zur Rampe aus hoch aufgeschichteten Quadern, die beidseits vom Fluss die Via Flamminia über die breite Senke führten. Zum Pilgerziel wäre es jetzt nicht mehr weit. Doch verlockender ist ein Abstecher auf den nahen Sorrate, dessen Kalkpyramide wie ein Vorposten die Stadt ankündet. Eremiten und Köhler haben ihn bewohnt. Horaz zog gemütlichere Orte vor: "Vides ut alta stet nive candidum Soracte ...» Doch oben leuchten HerbstGoldbecher und ein roter Glutball, dessen Untergang die vielen Ackerfeuer, ockerfarbenen Hügel und Stadtnester auf steilen Felsen langsam auslöscht. Wir sind die einzigen Gäste im nahen Kloster. Das Leben lärmt unten im Tal vorbei. Es geht auch ganz gut ohne Rom. 